\title{
The Spermiogram of Mesterolone Treated West African Dwarf Bucks with Testicular Degeneration
}

\author{
OYEYEMI, M. O., *ADENIJI, D. A. and OLUGBEMI, J.B.
}

Department of Veterinary Surgery and Reproduction, Faculty of Veterinary Medicine, University of Ibadan, Nigeria. *Correspondence: adejokebee@yahoo.com; da.adeniji@mail.ui.edu.ng; +2348033639792

\begin{abstract}
Summary
Twelve West African Dwarf bucks were used in this study to measure the effect of scrotal insulation and post insulation Proviron $®$ treatment on semen. The testes of the bucks were insulated using cellophane bags and cotton wool for 30 days. After the removal of the insulating materials, the bucks were divided into groups $A$ and $B$. Animals in group $A$ received $100 \mathrm{mg}$ per head per week of Proviron $\circledast$ (mesterolone) for 3 weeks while group B animals were left untreated. Semen collection was done using electroejaculation method throughout the study.

Results showed that scrotal insulation caused testicular degeneration evidenced by an insignificant reduction $(P>0.05)$ in sperm motility from $50.28 \pm 39.30 \%$ preinsulation to $41.81 \pm 30.80 \%$ during insulation. However, motility increased significantly $(P<0.05)$ to $74.58 \pm$ $13.73 \%$ in post insulation treated bucks. Mass activity was graded good $(++)$ pre-insulation, fair $(+)$ during insulation, very poor (0) post insulation and very good $(+++)$ during post insulation treatment phase. It was concluded that increased testicular heat due to scrotal insulation resulted in testicular degeneration and that the responses to proviron $®$ treatment in post insulation treated bucks confirmed the anabolic and androgenic properties of Proviron $\circledast$.
\end{abstract}

KEYWORDS: Spermiogram, mesterolone, electroejeculation, testicular degeneration

\section{INTRODUCTION}

Semen is the fluid discharged at ejaculation in the male consisting of spermatozoa in their nutrient plasma, secretions from the prostate, seminal vesicles and various other glands, epithelial cells and minor constituents (Blood et al., 2008). The Seminal plasma is the liquid supernatant obtained after centrifugation or sedimentation of semen. Semen in domestic animals consists of a variably dense viscid fluid in which motile spermatozoa are suspended (Laing, 1979).

Testicular degeneration occurs in response to raised intratesticular temperature, toxins, endocrine disturbances and infections, (Noakes et al., 2001). Scrotal insulation raises the temperature of the testis above normal body temperature whereas successful spermatogenesis can only occur at a temperature lower than that of the body (Matthew et al., 1975). Many of the causes of testicular degeneration do not manifest themselves in infertility immediately, due to protracted time taken for spermatogenesis. There is therefore normally a lag interval which may be of several weeks between the time at which the testis is damaged and the effects on semen quality are first noted (Noakes et al., 2001).

The major cause of infertility in the male is impairment of sperm quality, which is conventionally evaluated in terms of color, odor, viscosity, mass activity, motility, livability, volume, sperm count and concentration. Semen color is a reflection of concentration or presence of pigments or inflammatory products of infection (Ganong, 1997). Significant color change was also reported as a result of testicular insulation (Ajala et al., 2001). Under normal conditions, semen volume varies with species, breed, age, season, ejaculation frequency and mode of collection (Ganong, 1997). Ajala et al., (2001) observed that testicular insulation had no significant effect on the volume of the ejaculate. Sperm motility is evaluated as a percentage of motile cells (Ganong, 1997). It (in percentage) decreased significantly $(\mathrm{P}<0.05)$ in West African Dwarf Bucks during scrotal insulation (Ajala et al., 2001). Accurate determination of the number of spermatozoa per 
millilitre of semen is_important because it is a highly variable semen characteristic (Ganong, 1997). According to research reports, the average semen concentration value decreased significantly during insulation and at early post insulation while it increased gradually in late post insulation (Ajala et al., 2001). Semen contains a percentage of live and dead cells (Ganong, 1997). The minimum standard for quality semen is $75 \%$ live sperm cells. The average percentage live/dead cell ratio was observed to have decreased significantly during insulation and early post insulation while it later rose during post insulation (Ajala et al., 2001). Prolonged starvation has also been reported to have greatly reduced sperm cell liveability (Oyeyemi et al., 1998).

Mesterolone (Proviron ${ }^{\circledR}$, Schering AG, Germany) is a synthetic androgenic anabolic steroid that constitutes a class of natural and synthetic hormones often referred to as AAS (Anabolic/Androgenic Steroids). These steroids promote cell growth and division of several types of tissues including muscles, bone and germinal epithelium. The drug in man is administered orally and the initial recommended dosage is 75$100 \mathrm{mg}$ daily for several months, followed by maintenance therapy of 50-75 mg daily. Endocrine associated infertility in men such as deficient endogenous androgen formation, potency disorders, hypogonadism, aspermia and oligozoospermia have been successfully improved with Proviron ${ }^{\circledR}$ (Varma and Patel, 1988). This study was aimed at determining semen characteristics from degenerated testicles and to observe the effects of the anabolic steroid, Proviron ${ }^{\circledR}$ on testicular regeneration.

\section{MATERIALS AND METHODS Experimental animals}

Twelve apparently healthy West African Dwarf (WAD) bucks aged between 8 to 9 months and weighing between $6-10 \mathrm{~kg}$ were used for this study. All animals were examined for any probable congenital, acquired or anatomic defects such as cryptorchidism, testicular hypoplasia, testicular degeneration or sperm granulomas and inflammation. They were randomly assigned to 3 groups of 4 bucks per group.

\section{Study Location and Management of Experimental Animals}

The WAD bucks were housed in Ward II of the Veterinary Teaching Hospital University of Ibadan located between latitudes $07^{\circ}$ and $20^{\circ} \mathrm{N}$ and longitudes $30^{\circ}$ and $50^{\circ} \mathrm{E}$ with average humidity of $80 \%$, average ambient temperature of $34^{\circ} \mathrm{C}$ and total rainfall of $48^{\prime \prime}$. They were kept on litters of wood shavings. They were fed on fresh succulent hand cut grass and cassava peels supplemented with concentrate consisting of wheat offal, brewers grain and palm kernel cake at a rate of $0.5 \mathrm{~kg} / \mathrm{head} /$ day. Water was served $\mathrm{ad}$ libitum. They were allowed to acclimatize for 3 weeks during which they were dewormed, with Albendazole ${ }^{\circledR}$ bolus (Phemix, Belgium) at a dosage of $2 \mathrm{mg} / 10 \mathrm{~kg}$ body weight, vaccinated against Pestes des petite ruminantes and Tetanus using Peste de petite ruminant vaccine (PPR) and tetanus toxoid respectively.

\section{Scrotal Insulation}

A double layered cellophane bag with $0.5 \mathrm{~mm}$ thick cotton wool between the layers was used as the insulating material. It was wrapped around the scrotum, tied with thread and further sealed with adhesive for 30 days.

\section{Semen Collection}

Semen samples were collected from all animals using the electro-ejaculation method (Sailer et al., 1997) as control to the experiment on weekly basis for 3 weeks prior to insulation (preinsulation phases). This was to obtain the normal baseline values of the semen characteristics of the 12 bucks. The color, volume, live-dead ratio, mass activity, sperm concentration and sperm morphology were determined using conventional methods (Zemjanis, 1970) immediately after collection. Semen collection resumed four days after the insulation and at weekly intervals during the 30 days of insulation phase. All semen characteristics were also determined as before insulation. After the removal of the insulation materials ( $1^{\text {st }}$ day of post insulation phase), the bucks were separated into two groups A and B. Group A bucks (experimental bucks) were given the test drug Proviron ${ }^{\circledR}$ orally at a dose rate of $100 \mathrm{mg}$ per head per week for 4 weeks while the B group were left untreated and served as control. Semen collection and evaluation from each group resumed at weekly intervals after the test drug 
had been administered for 4 weeks.

\section{Semen analysis}

Collected semen was kept warm in a water bath maintained at $37^{\circ} \mathrm{C}$ and evaluation rapidly and effectively carried out so as to preserve the semen quality and characteristics. All materials were warmed before use. Color, density/viscosity, and presence of foreign materials were determined by visual assessment. Volume of ejaculate was determined from a graduated collecting tube. Sperm mass activity, progressive motility and live/dead cells ratio were determined by conventional methods (Zemjanis, 1970). Mass activity (Microscopic Wave Pattern or Swirl Motion) was observed with a drop of fresh semen on a pre-warmed slide without a cover slip and examined under $\mathrm{x} 4$ objectives.

\section{Motility}

A drop of semen mixed with warm sodium citrate as buffer was put on a warm slide and warm cover slip attached. The percentage of progressively forward motile spermatozoa with unidirectional rectilinear motion was estimated by rapid observation of 8-10 low power microscope fields under $\mathrm{x} 10$ objective (Zemjanis, 1970).

\section{Live/Dead Ratio}

A drop of semen was placed on a warm slide and mixed with a drop of warm eosin-nigrosin stain and was then observed under the microscope at x40 objective. Dead sperm cells picked up the stain and appeared purple while live sperm cells did not pick up stain and appeared as clear cells. Live/Dead count was determined from a total count of 600 spermatozoa in smears stained with Eosin-Nigrosin.

\section{Sperm Count}

The concentration was determined by the use of improved Neubaeur Haemocytometer (Deep 1/10 mm, LABART, Germany) as described by Zemjanis, (1970).

\section{RESULTS}

\section{Semen Characteristics}

During the preinsulation phase, the colors of the ejaculates were milky to creamy, watery-milky opalescent during insulation, opalescent during post insulation in the untreated group and milkycreamy during post-insulation in the treated group (Table I). Average ejaculate volumes were
$0.11 \pm 0.15 \mathrm{ml}$ during pre-insulation and $0.14 \pm 0.17 \mathrm{ml}$ during insulation but there after diminished significantly $(\mathrm{P}<0.05)$ to $0.04 \pm$ $0.03 \mathrm{ml}$ in the post insulation untreated bucks and again rose significantly $(\mathrm{P}<0.05)$ to $0.10 \pm$ $0.12 \mathrm{ml}$ in the post insulation treated group. The volumes of the ejaculates when compared across the experimental phases showed relatively little variation, but ejaculate volume showed significant $(\mathrm{P}<0.05)$ increase in post-insulation treated bucks (Table I). The mass activity during the pre-insulation phase was graded "good" $(++)$. There were waves, but no eddies. The mass activity was further markedly reduced (+0 ) during insulation and virtually absent (0) in post insulation untreated bucks but waves were dark and distinct with rapid motion in post insulation treated bucks. Mass activity was scored "very good" $(+++)$ (Table I).

Sperm percentage progressive motility decreased insignificantly $(\mathrm{P}>0.05)$ from an average of $50.28 \pm 39.30 \%$ pre insulation to $41.81 \pm 30.50 \%$ during insulation but was significantly lower $(\mathrm{P}<0.05)$ in post insulation untreated bucks $(26.67 \pm 14.97 \%)$ and then increased significantly $(\mathrm{P}<0.05)$ to $74.58 \pm$ $13.73 \%$ in post insulation treated bucks. The average live/dead ratio was $54.14 \pm 40.69 \%$ pre-insulation. This decreased insignificantly $(\mathrm{P}>0.05)$ to $48.56 \pm 31.07 \%$ during insulation and further decreased insignificantly $(\mathrm{P}>0.05)$ to $33.33 \pm 16.56 \%$ in post insulation untreated bucks. It however increased significantly $(\mathrm{P}<0.05)$ to $84.42 \pm 12.30$ in post insulation treated bucks (Table I, Figures 1 and 2). The mean sperm cell concentration was $101.86 \pm$ $72.04 \times 10^{6}$ spermatozoa/ml during pre insulation. This decreased insignificantly ( $P>0.05$ ) to $78.03 \pm 58.41 \times 10^{6}$ spermatozoa $/ \mathrm{ml}$ during the insulation phase and later decreased significantly $(\mathrm{P}<0.05)$ to $39.33 \pm 21.21 \times 10^{6}$ spermatozoa/ml in post-insulation untreated bucks and then increased insignificantly $(\mathrm{P}>0.05)$ to $67.10 \pm 30.19 \times 10^{6}$ spermatozoa $/ \mathrm{ml}$ in the post insulation treated bucks (Table I).

\section{DISCUSSION}

The reduction in semen characteristics such as mass activity, percentage progressive sperm motility, live/dead cell ratio and sperm cell concentration (Spermatozoa/ml) in all the bucks during scrotal insulation was in agreement with 
previous findings (Austin et al., 1961, Moule and Waites, 1963, Ajala et al., 2001) that elevated testicular temperature will affect normal sperm characteristics. Mieusset and Bujan, (1995) reported that increased testicular heat usually drives towards rapid shutdown of cellular activities which is often the cause of testicular degeneration and this agrees with results of this study since testicular temperature which reached $43.5^{\circ} \mathrm{C}$ caused testicular degeneration responsible for changes in semen physical characteristics such as color and viscosity. Hence semen color changed from milky-creamy during pre-insulation to watery-milky-opalescent during insulation to opalescent-watery during post-insulation untreated phase. The changes in color were a reflection of reduction in sperm concentration and mass activity during insulation and post-insulation untreated phases and this is similar to findings by Matthew et al. (1975). All the changes in color and reduction in semen characteristics have been attributed to a reduction in spermatids and spermatozoa number by a failure of spermatocyte cell stage to complete their maturation cycle (Sailer et al., 1997). The spermatocytes are the most susceptible cell type to heat; they are usually destroyed during scrotal insulation.

TABLE I: Mean changes in semen characteristics during the different phases of the experiment

\begin{tabular}{|c|c|c|c|c|}
\hline \multirow{2}{*}{ Parameter } & \multirow{2}{*}{ Pre - Insulation } & \multirow{2}{*}{ Insulation } & \multicolumn{2}{|c|}{ Post Insulation } \\
\hline & & & Untreated & Treated \\
\hline Colour & Milky - Creamy & $\begin{array}{l}\text { Watery - Milky } \\
\text { - Opalescent }\end{array}$ & $\begin{array}{l}\text { Opalescent - } \\
\text { Watery }\end{array}$ & Milky - Creamy \\
\hline Volume (ml) & $0.11 \pm 0.15^{a}$ & $0.14 \pm 0.17^{a}$ & $0.04 \pm 0.03^{b}$ & $0.10 \pm 0.12^{c}$ \\
\hline Mass Activity & ++ & +-0 & $0-0$ & +++ \\
\hline Motility (\%) & $50.28 \pm 39.30^{d}$ & $41.81 \pm 30.80{ }^{d}$ & $26.67 \pm 14.97^{\mathrm{e}}$ & $74.58 \pm 13.73^{f}$ \\
\hline Live ability (\%) & $54.14 \pm 40.69^{g}$ & $48.56 \pm 33.07^{g}$ & $33.33 \pm 16.56^{g}$ & $84.42 \pm 12.30^{h}$ \\
\hline Count $\left(\times 10^{\circ}\right)$ & $101.86 \pm 72.04^{i}$ & $78.03 \pm 58.41^{1}$ & $39.33 \pm 21.21^{j}$ & $67.10 \pm 30.19^{1}$ \\
\hline
\end{tabular}

Mean \pm Standard Deviation along the same row with same superscript do not differ significantly $(P>0.05)$

Mean \pm Standard Deviation along the same row with different superscripts differ significantly $(P<0.05)$.

Figure 1: Changes in mean progressive motility (\%) during preinsulation, Insulation and post-insulation untreated and treated WAD bucks

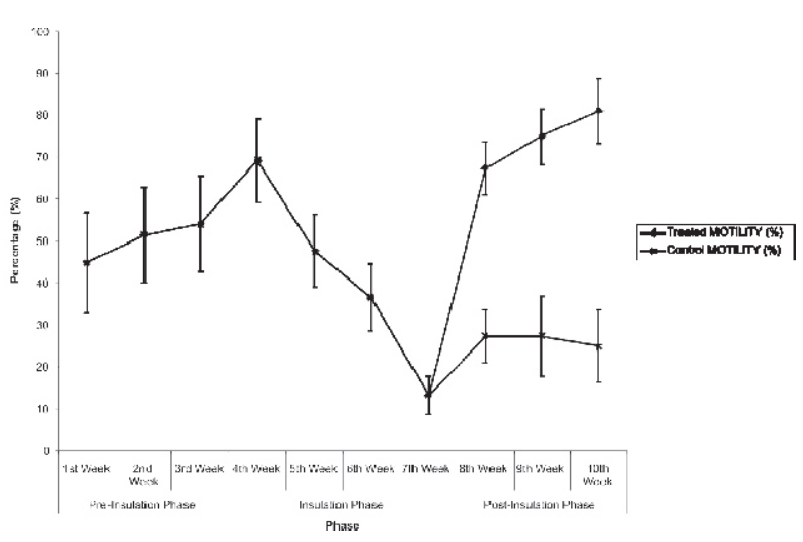

Figure 2: Changes in mean progressive livability (\%) during preinsulation; insulation and post-insulation untreated and treated WAD bucks

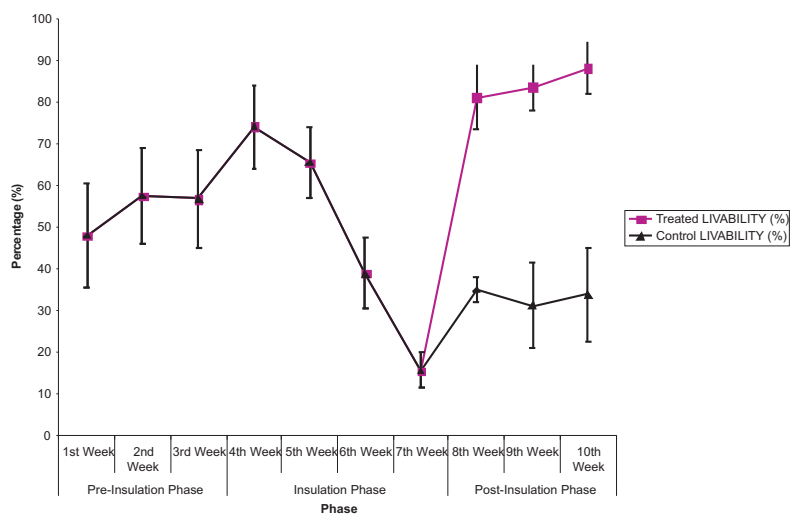


Figure 4: Effects of elevated testicular temperature on semen characteristics - motility (\%) and livability (\%)

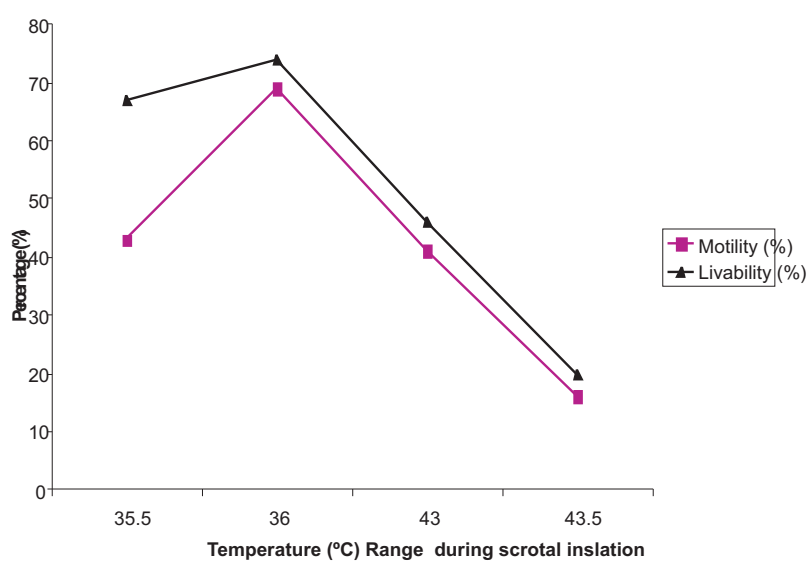

The sperm percentage progressive motility and the live/dead ratio increased steadily during the first 3 weeks of preinsulation and the first week of the insulation phases of the experiment. This therefore implied that spermatogenesis was still in normal progress and that the ejaculates during this period still consisted of normal testicular and epididymal spermatozoa that had matured and probably beyond where they may be affected by temperature changes. However, these two semen characteristics which initially dropped during the second week of insulation phase ultimately reached their least minimum values at the $7^{\text {th }}$ week (end of insulation phase).

Previous findings indicated similarity in seminal volume throughout the experimental period of preinsulation, insulation and post insulation phases because the contribution to volume is mainly by the accessory sex glands (Ajala et al., 2001) which were not affected by insulation. But contrary to the above finding, the seminal volume decreased significantly $(\mathrm{P}<0.05)$ in the post insulation untreated bucks and increased significantly $(\mathrm{P}<0.05)$ in the post insulation treated bucks in this study. The variations in volume in the post insulation untreated bucks agrees with previous findings in the bull where both the volume and composition of epididymal plasma change in accordance with a characteristic pattern along the duct (Crabo et al., 1971) and that any derangement of this function may affect epididymal contribution to seminal plasma since seminal plasma is a composite secretion arising from a number of sources including the testes, epididymides and accessory glands of the male (Hafez, 1993). The reduction in semen volume during insulation and particularly in post-insulation untreated group might be due to fluctuating epididymal sperm suspension during heat stress and was in agreement with findings (Noakes et al., 2001) that in ruminants, the volumes of the accessory secretion in the aggregate and the true (epidymal) sperm suspension are nearly equal, whereas in the stallion and boar the accessory secretions are greatly in excess. The semen characteristics such as progressive sperm motility (\%), live dead ratio (\%) and volume $(\mathrm{ml})$ increased significantly $(\mathrm{P}<0.05)$ over the preinsulation phase values in treated bucks due to the androgenic activity of the drug, mesterolone. It can therefore be concluded that increased testicular heat due to scrotal insulation can cause testicular degeneration and that the responses to Proviron ${ }^{\circledR}$ treatment in post insulation treated bucks confirmed the anabolic and androgenic properties of Proviron ${ }^{\circledR}$.

\section{REFERENCES}

AJALA O.O., OYEYEMI, M. O., AKUSU, M. O. and EIMUNJEZE H. E. (2001): The effects of scrotal insulation on the testicles and spermatozoa characteristics of West African Dwarf goats. Sokoto Journal of Veterinary Sciences, 3(1):44-50

AUSTIN, W., HUPP, E.W. and MURPHEE, R.I.(1961): Effects of scrotal insulation on semen of Hereford Bulls. J. Anim. Sc. 20:307-309.

CRABO, B., GUSTAFSSON, B., NICANDER, N and RAO, A.R. (1971): Subnormal testicular function concealed by phagocytosis of abnormal spermatozoa in the efferent ductules. J. Reprod Fert. 26:390-396.

GANONG W.F. (1997): Review of Medical Physiology. $18^{\text {th }}$ edition. A Simon and Schuster Company. 394-406.

HAFEZ E. S. E. (1993): Reproduction in Farm Animals $7^{\text {th }}$ edition. Lea and Febiger, Philadelphia. 165-187, 405-423.

LAING J.A. (1979): Fertility and Infertility in domestic animals. $3^{\text {rd }}$ edition. English Language book society edition (ELBS). 59-79.

MATTHEW, A., SILVA N. O. and AHMAD A.A (1975): Experimental testicular degeneration by scrotal insulation in a bull. $11^{\text {th }}$ FAO/SID. An International Postgraduate course on Animal production. Royal Veterinary College, Stockholm, Sweden 2-9.

MIEUSSET R. and BUJAN, L. (1995): Testicular heating and its possible contributions to male infertility: A review. Int. J. Androl. 18:169-184.

MOULE, O.K. and WAITES, O.M.H. (1963): Seminal degeneration in the ram and its relation to the temperature of the scrotum. J.Reprod. Fert. 5:433436

NOARKES, D.E., PARKINSON, T.J. and ENGLAND, C.W. 
(2001): Fertility and Infertility in male animals. In: Arthur's Veterinary Reproduction and Obstetrics. $8^{\text {th }}$ edition. Saunders Publishers, Edinburgh. 695-750.

OYEYEMI M.O., AJALA O.O., AKUSU M.O. and AGBESOLA O.O. (1998): The effect of starvation on semen characteristics of West African Dwarf Bucks. Proceedings of $3^{\text {rd }}$ annual conference of Animal Science Association of Nigeria. September 2224.128-130.

SAILER B. L., SARKAR, L.J., BJORDAHL J.A., JOST L.K., and EVENSON D..P. (1997): Effects of heat stress on mouse testicular cells and sperm chromatin structure. Int. J. Androl 18:294-301.

VARMA, T.R. and PATEL, R.H. (1988): The effect of mesterolone on sperm count, on serum follicle stimulating hormone, leutinizing hormone, plasma testosterone and outcome in idiopathic oligospermic men. Int. J. Gynaecol. Obstet. 26(1): 121-128.

ZEMJANIS R. (1970): Collection and Evaluation of Semen. In: Diagnostic and Therapeutic Technique in Animal reproduction ( $2^{\text {nd }}$ ed) $139-155$. 